\title{
PESQUISA CIENTÍFICA, CONHECIMENTO E EDUCAÇÃO: REFLEXÕES SOBRE SUA IMPORTÂNCIA ECONÔMICA E SOCIAL
}

\section{INTRODUÇÃO}

\author{
Márcia Jucá Teixeira Diniz1
}

Marcelo Bentes Diniz²

Um dos diferenciais do século XXI é a importância que a informação assumiu na vida cotidiana à medida que as tecnologias de informação e comunicação criaram e massificaram uma "nova economia", ditando um novo paradigma assentado em cinco características principais: informação como a matéria-prima sob a qual tecnologia hegemônica age; capacidade de penetração dessas tecnologias a lógica das redes em criar interações e conexões potencializando a difusão dessas informações; a flexibilidade com que processos, organizações e instituições podem ser modificadas e, por fim a convergência tecnológica em tornar a informação acessível e de certo modo útil (Castells, 2002).

A chamada Terceira Revolução Industrial sob o domínio das TCls, em especial no horizonte e escalas de comunicações criadas pelo sistema computador-internet veio permitir, segundo Rifkin (2012), a convergência da comunicação as novas formas de energia (renováveis) e a possibilidade de se criar uma rede de compartilhamento de energia, em substituição as fontes de energia baseada em combustíveis fósseis, que foram a base de sustentação da Segunda Revolução Industrial.

Ao mesmo tempo, a Quarta Revolução Industrial (Indústria 4.0) se caracteriza pela disseminação e diversificação das TCls nos produtos e processos, enquanto esforço cotidiano da busca por inovações, que passaram a se incorporar em todos os setores da economia e em grande parte dos bens de consumo duráveis. A automação, por meio de computadores; as interligações através de redes (sociais) virtuais; hardwares; softwares; aplicativos deram lugar a novas formas de conexão entre produtores (oferta) e consumidores (demandas), criando mercados longe de fronteiras físicas ou geográficas.

Cria-se cada vez mais uma integração presente e cotidiana entre os sistemas biológicos e os sistemas artificiais (Perelmuter, 2019), que interagem entre si tanto na produção como no consumo permitindo um ciclo de inovações que antes só podia ser pensado na ficção científica, como é o caso dos carros autônomos (sem motorista), as smart home, com recursos tecnológicos da domótica - tecnologia responsável pela gestão dos recursos disponíveis em uma habitação automatizados e interligados em um único dispositivo, operações médicas à

\footnotetext{
1 Professora do Programa de Pós-graduação em Economia da UFPA.

${ }^{2}$ Professor do Programa de Pós-graduação em Economia da UFPA.
} 
distância, drones teleguiados a quilômetros de distância que podem realizar desde tarefas simples como fotografar, filmar ou fazer entregas a tarefas complexas como servir como armas de guerra no lançamentos de foguetes e para espionagem.

Mas à medida que a informação se disseminou, manifesta em diferentes bens de informação (livros, bancos de dados, revistas, filmes, música, cotação de ações, páginas da Web), ela fez evoluir a tecnologia da informação, ou seja, a infraestrutura tecnológica que permite armazenar, buscar, acessar, transmitir, copiar, filtrar, manipular, visualizar e reproduzir esses bens de informação (Shapiro; Varian, 1999).

A sociedade do conhecimento é dependente da informação, mas ela se diferencia pela velocidade com que o conhecimento é criado, acumulado e, ao mesmo tempo, perde sua relevância e valor econômico, a partir de como e educação codifica esse conhecimento, como algo útil individualmente, mas principalmente, socialmente, resultado do próprio progresso técnico e científico (David; Foray, 2003).

Portanto, o conhecimento (científico) tem como principal diferencial em relação à informação (geral), na forma como este é codificado e qualificado separando-se como um tipo de informação particular fruto da aplicação do método científico e seus mecanismos de geração pela aprendizagem e experiência e transmissão via, fundamentalmente, o ensino formal e os canais de comunicação trazidos pela academia, isto é, as instituições onde esse conhecimento foi formado e testado a luz da ciência. Portanto, a sociedade da informação para se tornar exitosa transformou-se em sociedade do conhecimento. E, não apenas o conhecimento abstrato, mas, principalmente, àquele que pode ser aplicável, fruto de uma elaboração anterior e de um processo de aprendizado acumulado e registrado que é repassado entre gerações, seguindo um método e procedimentos formativos através da educação.

Assim, o conhecimento assumiu uma forma intangível de capital que é incorporado na economia como duas categorias principais (David; Foray, 2003): enquanto investimento voltado para a produção e disseminação de conhecimento, aqui aparecem o treinamento e a educação, categorias relacionadas diretamente como o capital humano e, ainda, pesquisa e desenvolvimento [P\&D], informação e coordenação; mas também, como investimentos voltados para a manutenção do estado físico do capital humano (gastos com saúde).

Dada à condição diferencial da produção e disseminação do conhecimento, especialmente, a partir da educação, interessa entender sua condição estratégica na economia contemporânea, daí o objetivo principal deste artigo: discutir a interpretação da ciência econômica acerca da educação e da produção do conhecimento via pesquisa, desenvolvimento, 
ciência e inovação, inclusive, ressaltando o papel do Estado e da política pública em sua promoção e disseminação.

Ao encontro do objetivo acima o artigo está divido em três seções, a primeira discute os fundamentos teóricos do conhecimento e da educação, enquanto geradores de externalidades e com características de bens públicos. A seção 2 discute a discussão da Teoria do Capital Humano no entendimento do conhecimento e educação. A terceira seção apresenta a discussão neochumpteriana consoante às abordagens dos Sistemas de Inovação e Hélice Tríplice e 0 papel das Universidades na Produção do Conhecimento e Inovação. A quarta seção tece algumas considerações finais.

\section{CONHECIMENTO E EDUCAÇÃO: EXTERNALIDADES E BENS PÚBLICOS}

A compreensão do efeito que o conhecimento, educação, pesquisa e o desenvolvimento científico tecnológico podem ter como um bem diferenciado na sociedade deriva dos conceitos de externalidades e bens públicos.

A presença de interdependência entre os agentes econômicos no qual a decisão de um agente econômico afeta o resultado econômico de outro agente econômico, significa que existem benefícios e custos que são incorporados na função objetivo do agente, que não resulta de suas escolhas, mas são impactos gerados pela decisão de terceiros. Todavia, esta interdependência embora seja condição necessária não é condição suficiente para a existência de externalidade. A segunda condição, que assume a forma de condição suficiente para a existência de uma externalidade é o fato que o efeito positivo (benefício) ou negativo (custo) gerado sob terceiros não seja compensado entre os agentes envolvidos na relação (Baumol; Oates, 1988). Se o efeito sofrido for positivo, o agente que recebe 0 efeito da externalidade deveria em princípio compensar o agente gerador do efeito externo, entretanto, o contrário ocorreria se o efeito sofrido da externalidade fosse negativo, tal que, em princípio, este deveria ser compensado pelo agente gerador do efeito externo.

Observa-se que nos termos acima que o efeito externo produzido não é resultado de uma ação deliberada, mas sim de uma ação não-intencional ou incidental, tal que assume a forma de um subproduto de uma atividade legítima (Mishan, 1971).

Por outro lado, considera-se um Bem Público puro, como àquele que reúne duas características opostas a um bem privado: não-rivalidade e não-exclusão. Por não-rivalidade considera-se que a provisão de um bem (ou insumo) para um agente econômico qualquer, digamos $A$, implica a mesma provisão para outro agente, digamos $B$, quer este queira ou não 0 bem. Assim, o consumo do bem por um indivíduo não diminui o montante disponível do bem 
para outro indivíduo (Kolstad, 2000; Pereira, 2013). Isto significa que seu consumo é simultâneo e o benefício derivado deste consumo é indivisível. E, portanto, em termos físicos os indivíduos não concorrem ou disputam pela aquisição dos mesmos bens (insumos).

Observe-se, que enquanto que no caso de bens rivais, o consumo conjunto é a soma dos consumos individuais das quantidades consumidas por cada um e, assim, a procura de mercado é a soma das procuras individuais, o que difere, portanto, do consumo de um bem não rival.

A não exclusão é uma característica que se expressa pelo fato que 0 indivíduo $A$ qualquer ao consumir um bem não impede que um indivíduo $B$, ou qualquer outro indivíduo, possa consumi-lo e obter seus benefícios.

Devido as características de não-rivalidade e não-exclusividade dos bens públicos, sua provisão (oferta) ou disponibilidade de dotação para um indivíduo implica a provisão (oferta) ou dotação para todos os demais, embora, o consumo ao longo do tempo pode diminuir a oferta ou dotação disponível - a quantidade total do bem público que todos consomem, diminuindo as possibilidades de acesso ou provisão e, portanto, diminuindo o grau de não exclusão.

Além disso, devido as características de não-rivalidade e não-exclusividade todos os indivíduos vão consumir a mesma quantidade do bem público. Daí porque há um incentivo para que os indivíduos atuem como caronas (free riders), no sentido de se aproveitar do benefício do consumo do outro. Isto significa que os indivíduos se aproveitam sem participação e esforço, gozando das externalidades positivas das ações dos outros. E, consequentemente, em muitos casos a oferta de bens públicos é insuficiente (ineficiente), enquanto atividades que a todos se beneficiam, por falta de incentivos.

Uma classificação intermediária entre bens privados e Bens Públicos, são os chamados Bens de Clube. Estes são bens de consumo coletivo e por terem uma capacidade limitada, uma vez que existe até um certo nível de utilização, existe uma rivalidade parcial no consumo. Assim, agentes adicionais que consomem o bem ou serviço, geram uma externalidade negativa sob os demais agentes que já o consumiam, sob a forma de congestionamento e, consequentemente, a exclusão é praticada como forma de racionalizar esse uso.

Outra característica é que a existência de utilizadores (agentes) adicionais pode gerar uma externalidade positiva na forma diminuição do preço (taxa ou tarifa) para utilização do bem (economias de escala). Do ponto de vista do consumo coletivo, todos os "clubes privados" são bens de clube e, também, o são quase todos os serviços públicos, em que é passível uma rivalidade parcial no consumo e, ao mesmo tempo, praticar preços (taxas, tarifas) aos utilizadores. São exemplos, pontes, autoestradas, museus, aeroportos, entre outros. Existem 
bens de clube, como escolas, hospitais (campanhas de vacinação), tribunais, universidades, entre outros, que além de gerar resultados individuais (privados) àqueles que diretamente se beneficiam dos serviços de ensino, saúde ou justiça, geram benefícios indiretos aos restantes dos indivíduos da sociedade.

Importa observar, que na maioria dos bens públicos e bens de clube, a característica da não exclusão se manifesta por não existir ou ficar difícil de definir o direito de propriedade.

No caso da exclusão existir por uma imposição legal, como através do direito de propriedade, isto descaracteriza o bem como público, tornando-o um bem de clube, um monopólio natural ou mesmo um bem privado (cujo consumo pode ser repartido). A propriedade pode ser pública, privada ou comunal, conferindo a diferentes tipos de entidade a possibilidade de praticar a exclusão. Se pública (estado); se privado (indivíduo ou empresa) e se coletiva, através de várias formas: clubes privados, associações, condomínios, cooperativas, entre outros.

Por outro lado, existem três tipos de bens públicos globais. O primeiro são os Global Human-made Commons, que consistem em atividades, tratados e normas desenhados para orientar a interação entre agentes e prestar suporte ao desenvolvimento de indivíduos, sociedade e países, ex. sistemas de transporte e comunicação, tratados internacionais, conhecimento não comercial, normas, etc. O segundo são os Global Policy, orientados a procurar benefícios sociais de ordem mundial, ex. paz e seguridade, estabilidade financeira, saúde, educação básica. Estes dois tipos de bens públicos globais são desenhados pelas comunidades e instituições.

O terceiro são os Global Natural Commons compostos pelos recursos naturais (bens comuns) de domínio público global (Kaul e Mendoza, 2003). Global Natural Commons são partes da Terra cujos domínios estão fora de jurisdição nacional e todas as nações têm acesso: oceanos, antártica, atmosfera e espaço (Rockström, 2017).

Importa dizer que a presença de externalidades e de bens públicos tomam a forma de falhas de mercado, em vez que possibilitam uma diferença entre custos privados e sociais, bem como, benefícios privados e sociais.

Entende-se que o conhecimento produzido e socialmente divulgado, especialmente, pelos meios acadêmicos, torna-se apropriável por quaisquer cidadãos em qualquer lugar, independente de atributo físico ou social e de forma atemporal, de sorte que seu nível de consumo e utilidade dele derivada não diminui a disponibilidade "desse conhecimento" para qualquer outro cidadão poder dispor e usufruir de seus benefícios. Desse ponto vista, para Ciência Econômica, por reunir características de não-rivalidade e não-exclusão o conhecimento é aceito na literatura no rol dos Bens Públicos ou mesmo de Bens Públicos Globais (Stiglitz, 
1999a; 1999b; Tilak, 2008), muito embora a educação e, em particular a educação superior possa pensada mais próximo da terminologia de um bem publico (no singular) (Marginson 2007; 2011), enquanto congrega atividades conjuntas e coletivas e que gera benefícios sociais que podem, em princípio, ser aproveitados por todos, inclusive na forma de externalidades.

A condição do conhecimento como um bem público global deriva de seu caráter transfronteiriços, onde o local de sua produção não vincula a ele seus benefícios. Ademais, além de não existirem fronteiras físicas geográficas a sua divulgação e disseminação, e isto tomou uma dimensão maior a partir da disponibilidade da internet e seu acesso público, não estabelece regras ou restrições a indivíduos com diferentes características, sejam elas atributos inatos ou adquiridos individualmente ou socialmente. Desse modo cidadãos de diferentes origens, etnias, religiões ou crenças, idade, sexo, condição social ou econômica, podem acessar e dispor de tais conhecimentos produzidos e colocados de forma livre na rede. Mesmo existindo restrições a certos conhecimentos dispostos na internet, o seu conteúdo de livre acesso, e disponível sem nenhuma barreira social.

Ao mesmo tempo, é preciso dizer que o que foi produzido de conhecimento e se torna público pelos diferentes canais de comunicação, linguagem oral, escrita, digital, virtual, tem caráter intertemporal. É preciso atentar, entretanto, para quais os canais de formação desse conhecimento, seus mecanismos de transferência entre os agentes econômicos, as instituições que dominam esses mecanismos.

Ademais, uma característica diferenciada da produção do conhecimento hoje é que embora continue tendo um alto custo fixo para ser produzido, as tecnologias de informação e comunicação tornaram sua reprodução (custo marginal) muito baixa (quase zero) dada à escala que as redes de informação como a internet atingiram. Segundo Shapiro e Varian (1999) um dos diferenciais da tecnologia digital é a possibilidade de redução muito significativa tanto do custo de reprodução, quanto do custo de distribuição.

Assim, o número de visualizações dos textos e downloads realizados é quase ilimitado se não existir nenhuma restrição técnica ou legal ao número de usuários que irão compartilhar daquela informação (conhecimento produzido). Em verdade, às possibilidades de congestionamento que o número de acessos simultâneos pode ter pode criar tecnicamente uma externalidade negativa entre esses usuários.

Pode-se pensar em diferentes níveis a partir das quais estas externalidades educacionais atuam. Externalidades de alcance geral, no qual a educação é um meio de oportunidade de passar a uma condição social superior. Assim, a educação é uma forma de diminuir a desigualdade econômica e a pobreza, como mencionado na Figura 1. Ganhos de 
escolaridade em qualquer nível aumentam as habilidades laborais, a produtividade e, consequentemente a remuneração.

Assim, um primeiro efeito apontado pela literatura, derivado de uma externalidade positiva provocada pela educação é o seu efeito distributivo, tal que a educação permite a redução das desigualdades em um contexto mais amplo, mas também em diferentes estratos da sociedade, como por exemplo, entre gênero e diferentes grupos étnicos e raciais, conferindo a educação uma avaliação, que vai além do seu caráter de eficiência, mas incorpora um forte elemento equitativo, que pode ser dito é mais intenso, quanto maior a desigualdade de renda e de oportunidades dessa sociedade.

Se entendermos a pobreza como algo relacionado a um estado de múltiplas carências, 0 que implica aumento das restrições que um agente econômico tem na tomada de decisões, a educação e, consequentemente o acúmulo de conhecimento por um indivíduo pobre expande seu horizonte de possibilidades a despeito de seu background familiar.

Todavia o efeito da educação sobre a desigualdade pode assumir uma configuração diferente do ponto de vista macroeconômico. Segundo Ram (apud Menezes-Filho, 2001), existem duas formas através das quais a educação pode afetar a desigualdade, uma com impacto negativo e outra com impacto positivo sobre a mesma. Uma expansão educacional a partir de níveis educacionais baixos tende a aumentar a desigualdade, uma vez que aumenta os desvios educacionais entre a nova geração que receberá maior instrução e a antiga que não se beneficiara diretamente da mesma. Por outro lado, a expansão educacional pode ter um impacto redutor das desigualdades na medida que diminui os diferenciais de salários associados à mesma em cada momento. Todavia, esse canal atua em consonância com a demanda e a oferta pelos vários grupos educacionais; o viés tecnológico (que atua diretamente sobre a demanda); 0 comércio internacional; e os padrões de consumo interno e crescimento da renda. 


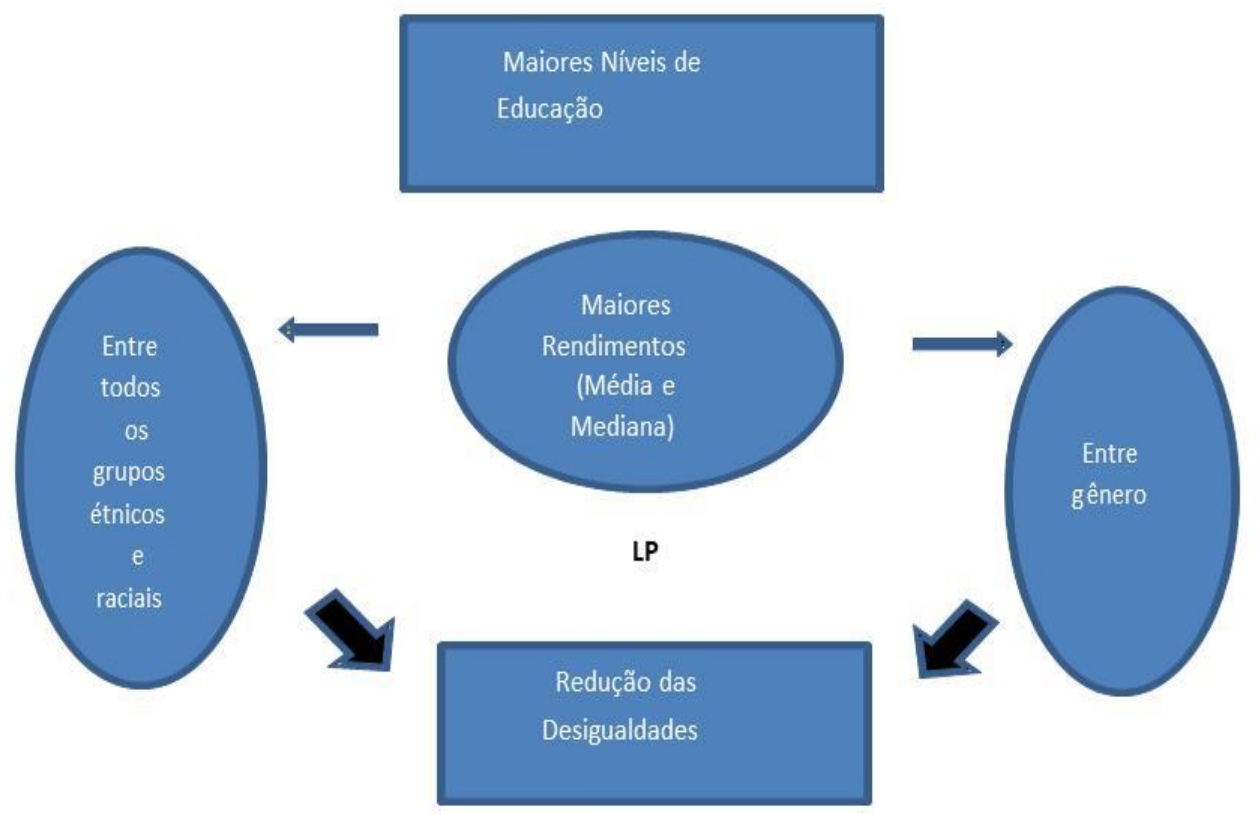

Fonte: Adaptado a partir de: Baum; S.; Payea, K. (2005).

Outros estudos empíricos apontam uma classe de benefícios macroeconômicos e microeconômicos da educação, seja por que geram direta ou indiretamente benefícios (privados/sociais) seja por que evitam custos (privados/sociais). Nesta direção, segundo Haverman e Wolfe (1984); Baum e Payea (2005) e loschpe (2016), pode-se identificar, pelo menos dezoito formas de externalidades que a educação (incluso a educação superior) afeta 0 bem-estar da sociedade, cuja natureza econômica do impacto pode expressar um canal de ligação apenas privado, mas, também, como bem público. Algumas delas, segundo o canal de impacto seriam: a) elevação da produtividade individual no mercado; b) aumento da remuneração não pecuniária no mercado de trabalho; c) aumento indireto das oportunidades de lazer, em consequência da elevação da renda; d) crescimento da produtividade individual na produção do conhecimento, o que resulta indiretamente no crescimento quantitativo e qualitativo do capital humano. Além dessas, haveriam outras, com a natureza de bem público: 1. redução da criminalidade; 2. elevação da coesão social; 3. melhora da mudança tecnológica; 4. melhora na distribuição de renda. 
Figura 2: Outros Benefícios Indiretos (Sociais) Apontados pela Literatura

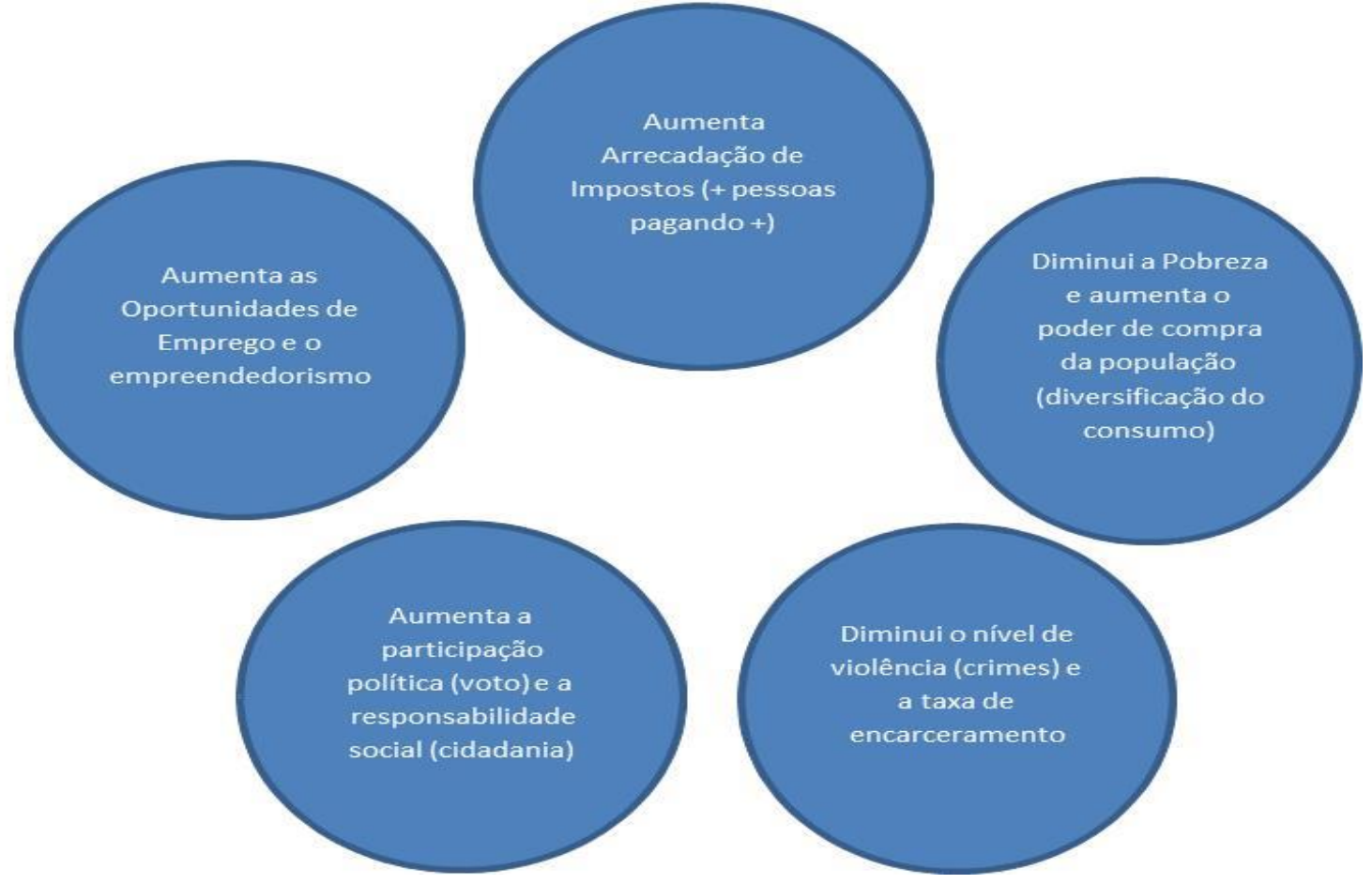

Fonte: Adaptado a partir de: Baum; S.; Payea, K. (2005).

Os canais a partir dos quais estas externalidades se manifestam podem variar entre as economias, guardando uma relação dinâmica com a estrutura produtiva; com a infraestrutura instalada das unidades de pesquisa e ensino, desenvolvimento científico tecnológico e acúmulo de conhecimento e inovação, bem como, de suas instituições e instrumentos de financiamento, sejam públicos ou privados e; o grau de articulação entre eles, tal que os diferentes indicadores de desempenho da expansão dos elementos sejam convergentes na direção de tornar o país mais competitivo e desenvolvido.

No caso específico da educação decorrente de processos de ensino/aprendizagem toda a sociedade se beneficia de mão-de-obra mais qualificada via menor incidência e de transmissão de doença (serviços de saúde), pela adoção de práticas de higiene e cuidados preventivos que uma pessoa com maior grau de escolaridade passa a ter; os indivíduos buscam exercitar um maior sentimento de justiça, sendo mais cumpridores de seus deveres, avessos a práticas de corrupção, aderentes a campanhas que visam o bem comum, entre outros. Assim, foram evidenciadas empiricamente uma correlação positiva entre maiores níveis de educação e melhora da percepção sobre a saúde; aumento da expectativa de vida; aumento da consciência ambiental; aumento do voluntarismo a causas sociais; aumento da doação de sangue e do nível de leitura, entre outros (Baum; S.; Payea, K., 2005). 
Figura 3: Outros Benefícios Individuais com Repercussão Social

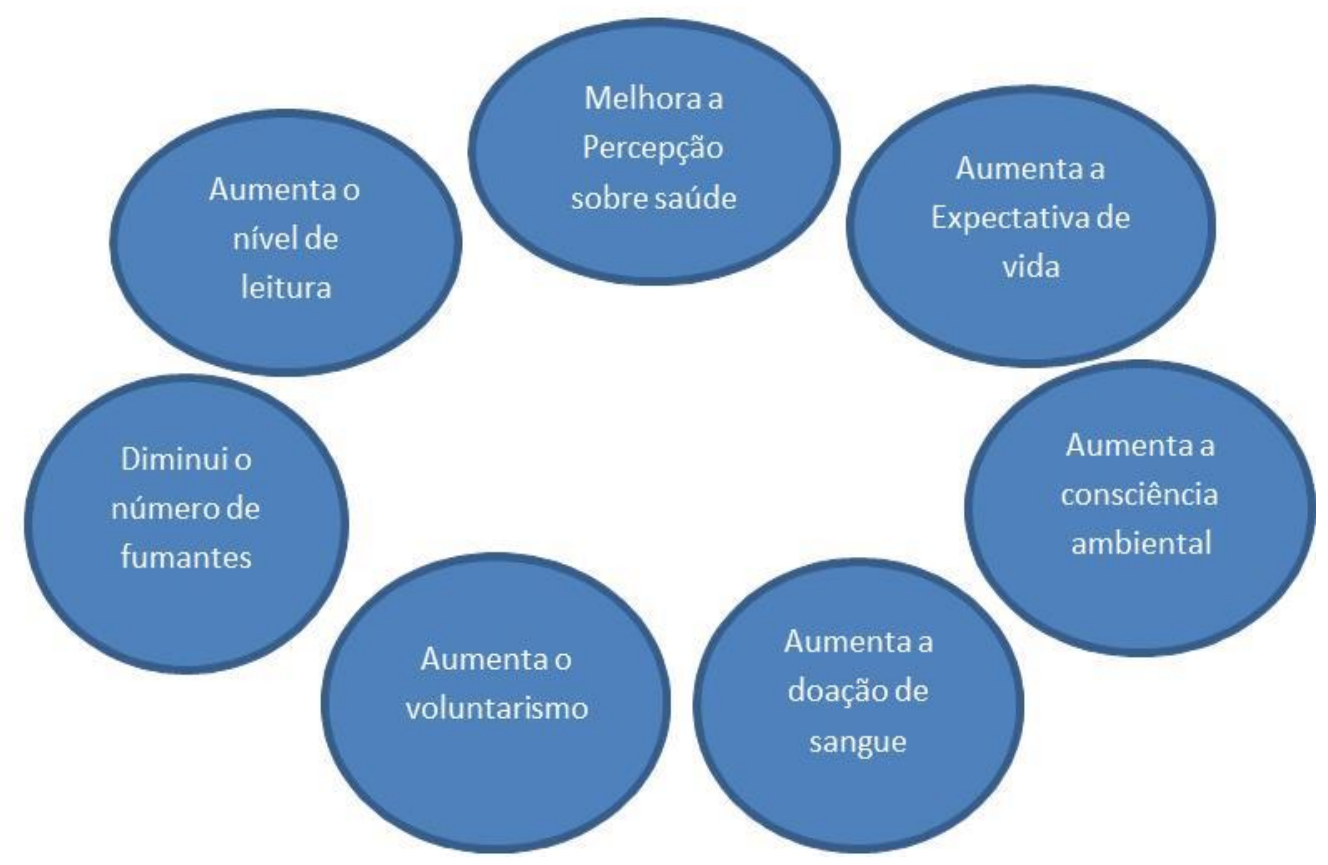

Fonte: Adaptado a partir de: Baum; Payea (2005).

Por outro lado, considerando o papel da pesquisa básica, existe a percepção de que 0 valor econômico por ela gerada é difícil de ser previsto e, portanto, medir de forma retrospectiva os resultados da pesquisa, e, assim por consequência, os pagamentos das descobertas científicas demandam um longo prazo (Pavitt, 1991; Dasgupta, David, 2003). Além disso, os retornos decorrentes dos avanços da pesquisa básica são limitados por que os direitos de propriedade envolvidos nessas descobertas são intrinsecamente difíceis de estabelecer e defender. Daí resulta que os retornos privados ao investimento em pesquisa básica são altamente incertos, principalmente, em relação aos benefícios que serão acumulados na sociedade como um todo.

Assim, por suas características específicas, pode-se colocar a pesquisa básica, também, no contexto de bens públicos globais (Anand, 2002; Kaul; Mendoza, 2003, Kaul, 2005), onde se espera que o retorno econômico para a sociedade seja bastante grande comparado ao valor investido, apenas considerando que um avanço fundamental no conhecimento que ela gere pode servir como um insumo para pesquisa aplicada e esforços de comercialização, levando, inclusive ao surgimento de muitos novos produtos e processos (Dasgupta, David, 2003).

Rosenberg e Nelson (1994) e Mowery Rosenberg (1999) atribuem as universidades e 0 papel dos fundos públicos no financiamento da pesquisa voltada a educação superior nos EUA 
antes mesmo da II Guerra Mundial como tendo papel decisivo para liderança tecnológica e econômica dos Estados Unidos nos pós-guerra.

\section{EDUCAÇÃO, CONHECIMENTO COMO DECISÕES DE INVESTIMENTO: A CONTRIBUIÇÃO DA TEORIA DO CAPITAL HUMANO}

Embora outros economistas como Marshall, Friedman, Clark, Kuznets (Saul, 2004; Nakabashi, 2005) já haviam percebido que a aquisição de habilidades através de diferentes formas de aprendizado incorporadas pelo próprio indivíduo poderia aumentar o desempenho do fator trabalho, inclusive, sua produtividade, e, consequentemente, o resultado esperado pelas empresas, é atribuído às contribuições de Becker (1962; 1982), Schultz (1961) e Mincer (1958) 0 papel seminal do desenvolvimento daquilo que passou a ser denominado de Teoria do Capital Humano.

Esses autores tornaram claro, que o trabalho não pode ser pensado como um fator de produção homogêneo, pela capacidade de apreender dos trabalhadores, ao mesmo tempo, existiriam formas diretas e indiretas de tornar mais produtivo este trabalho. Assim, haveriam diferenciais no processo de treinamento o "on-the-job training"; treinamento geral e específico; estudo, ou mais especificamente educação formal; outros conhecimentos; aumento da saúde física e emocional do trabalhador e de sua família (Becker, 1962; 1982);

Ao mesmo tempo, passam a defender algo que pareceria muito diferente à época 0 "investimento em capital humano". O homem seria ele mesmo uma forma de "capital good", conforme Shultz (1961), que toma decisões como auto-investimento pessoal que toma forma de capital por que seu retorno decorre do aumento da renda futura. A ideia é que na escolha entre 0 tempo alocado e o lazer, o indivíduo possa abrir mão de parte do tempo que destinaria para 0 trabalho e, portanto, com um custo de oportunidade sobre renda presente, para ter um ganho adicional de renda após ter concluído os estudos, uma vez que terá incorporado conhecimento se traduzindo em aumento da habilidade laboral e, consequentemente, de sua produtividade.

$\mathrm{O}$ que mais tarde foi denominado na literatura de prêmio por ano de estudo, significa 0 diferencial de renda que indivíduo ganha na comparação da sua renda presente a renda futura por cada ano adicional de estudo (Mincer, 1958). Além disso, Mincer (1958) sustenta que o diferencial de rendimento entre diferentes tipos de ocupação e, portanto, de desigualdade de renda entre elas, poderia ser atribuída ao diferencial de investimento em capital humano feitos pelas pessoas e, ademais, em períodos de maior mudança tecnológica, o preço da "habilidade" é 
mais valorizado por que além das "pessoas educadas" serem boas inovadores a educação a elas conferidas acelera o processo de difusão tecnológica (Nelson; Phelps, 1966).

Acontece que este diferencial de renda depende do mercado de trabalho, das relações sociais e tecnologia média da sociedade, que vai demandar qualificações e formações de acordo com as caraterísticas das estruturas de produção e dessa tecnologia. Assim, o tamanho do esforço e o custo de oportunidade de se abrir mão da renda presente não são os únicos elementos que definem o diferencial de renda e funcionam como elemento motivador da demanda por educação. Ademais, indivíduos de classes sociais diferentes têm oportunidades diferentes de educação e da própria capacidade ou não de abrir mão da renda presente. Portanto, pode-se até pensar em um custo de oportunidade médio da educação em uma dada economia, mas os pobres, àqueles que só dependem de si mesmo para constituir a renda presente e em muitos casos de sua família, tem um custo de oportunidade adicional em sua decisão de investir em capital humano.

A importância macroeconômica do capital humano ocorre com a chamada Nova Teoria do Crescimento Econômico a partir da segunda metade da década de 1980. Os trabalhos seminais de Romer (1986; 1990; 1993; 1994); Lucas (1988); Azariadis; Drazen, 1990; Mankiw, Romer, Weil, (1992); Benhabibi; Spiegel, 1994, Barro (2001), permitiram a quebra de alguns pressupostos iniciais do modelo de Solow (1956), seja introduzindo o "capital humano" como uma variável direta na função de produção, medida, por exemplo, como anos de estudo (ponderado ou não pelo IDH), ou seja, como efeitos de economias externas, que este capital humano gera sobre os outros fatores de produção, e, como consequência, permitindo a possibilidade de retornos não-decrescentes dos fatores de produção, bem como retornos crescentes da função de produção, levou entre outros, a possibilidade para o surgimento de outra classe de modelos de crescimento - modelos de crescimento endógeno.

Outro aspecto importante da "introdução" do capital humano nos modelos de crescimento foi mostrar a sua interação com outras formas de capital

Além disso, os desenvolvimentos ocasionados pela teoria do capital humano permitiram outros insights acerca dos efeitos da educação sobre a economia e a cultura como (Nakabashi, 2005, p.9): 1) os rendimentos, usualmente, se elevam com a idade a uma taxa decrescente. A taxa de crescimento tende a ser positivamente correlacionada com o nível de qualificação, enquanto que o seu decréscimo tem uma correlação negativa; 2) taxas de desemprego tendem a ser negativamente correlacionadas com o grau de qualificação; 3) firmas, em países subdesenvolvidos, tendem a ser mais "paternalistas" com os empregados em relação aos países desenvolvidos; 4) pessoas mais jovens mudam de trabalho com maior freqüência e recebem 
mais investimento, tanto no trabalho, quanto fora dele; 5) a distribuição de renda tende a ser "positively skewed", principalmente entre trabalhadores mais qualificados; 6) pessoas com mais habilidades recebem mais educação e outros tipos de treinamento; 7) a divisão do trabalho é limitada pela extensão do mercado; e 8) o investidor típico em capital humano é mais impetuoso e, portanto, mais propenso a cometer erros em relação ao investidor típico em capital físico.

\section{CONHECIMENTO, EDUCAÇÃO, INOVAÇÃO E O PAPEL DAS UNIVERSIDADES NO CONTEXTO DA VISÃO NEOSCHUMPETRIANA}

No âmbito da corrente Neoschumpeteriana podem-se destacar três abordagens pelas quais a educação e o papel das universidades são tratados: a abordagem do Sistemas de Inovação; a abordagem "Triplice Hélice" e a abordagem da Universidade Empreendedora.

\subsection{SISTEMAS DE INOVAÇÃO}

No âmbito dos Sistemas de Inovação, entende-se que o acúmulo do conhecimento, a pesquisa básica e o desenvolvimento tecnológico são exercidos fundamentalmente pelas universidades, esta é basilar tanto na formação da mão-de-obra qualificada para o sistema produtivo, como na construção de competências, que concorram para o processo inovativo (Lundvall e Cristensen, 1999; Lundvall, 2005). Assim, no contexto da abordagem do Sistema de Inovação, as universidades cumprem três funções complementares: realiza o processo geral de pesquisa científica (básica e aplicada), o que afeta a fronteira tecnológica da indústria, (Rogers, 2003); produz conhecimento diretamente aplicável a produção industrial (inclusive direcionado e partir de suas demandas) e, fornecem insumos para inovação industrial como capital humano que pode realizar pesquisas para a indústria ou engajar-se diretamente na mesma.

Todavia, para Dosi (1991), é necessário distinguir o conhecimento tecnológico do conhecimento científico. O conhecimento tecnológico tem um caráter local (diferente do conhecimento científico, cujo fluxo de informações atravessa fronteiras), no sentido de que o que se aprende hoje depende da "história anterior" dos êxitos e fracassos. As habilidades, as competências e as capacidades organizativas de caráter tecnológico se desenvolvem de forma incremental, partindo de experiência e vantagens anteriores. Dessa forma, o conhecimento tecnológico é muito mais difícil de ser transmitido do que o conhecimento científico (Dosi, 1991).

Por outro lado, o conhecimento tecnológico e também o paradigma intelectual são necessários para deslocar novas possibilidades técnicas de produto e processos inovadores e 
fluem entre as diferentes comunidades com as mesmas dificuldades que entre mercados. Em consequência geram distintas direções e "trajetórias tecnológicas" (path dependence) ${ }^{3}$.

Ainda segundo Dosi (1991), o conhecimento tecnológico se acumula nas empresas na forma de trabalhadores especializados, de tecnologia própria e Know-how, difícil de copiar, o que é similar à própria expertise atribuída ao capital humano. Este conhecimento tácito não comercializado é o que parece de maior importância durante a fase inicial de desenvolvimento de um novo produto ou processo.

Por outro lado, como assinala Cimoli (2014), é preciso pontuar que a influência do SNI sobre o desempenho da economia, especialmente relacionado promoção do crescimento e desenvolvimento econômico, não é linear e determinística, mas está vinculado a como os elementos de $P$ \& $D$, bem como, a expansão da base da ciência e tecnologia e acesso a educação, se transformam em vetores afirmativos na construção de uma competência para a performance da economia, traduzido em elementos como, maior produtividade, inovação, exportação de bens mais intensivos em tecnologia, entre outros. E isto, tem uma relação sistêmica, também, com a própria condução da política macroeconômica e as estruturas e arranjos institucionais que o país escolhe, como: o sistema de direitos de propriedade, os mecanismos de regulação de mercado, a política industrial e de comércio exterior, entre outras.

De outra parte, um Sistema Nacional de Pesquisa e Desenvolvimento ou um Sistema Nacional de Inovação interage empresas públicas e privadas, Universidades e laboratórios do governo, visando a produção e a utilização da ciência e da tecnologia dentro das fronteiras nacionais (Niosi et al., 2000). Essa interação tem como objetivo o desenvolvimento, à proteção, 0 financiamento ou à regulamentação da "nova" ciência e tecnologia (inovação), ou o desenvolvimento econômico de uma região. Em verdade, compreende uma rede de instituições e agentes públicos e privados de apoio à empresa com atividades científicas e tecnológicas, incluindo a investigação e o desenvolvimento, a difusão de tecnologia e a criação de capital humano técnico (Dahlman e Frischtak,1990; Nelson e Rosenberg, 1993; Freeman, 1995; Niosi et al., 2000; Lundvall, 2003, 2005; Edquist, 2009).

Observa-se que a pesquisa acadêmica, essencialmente a pesquisa básica, enseja muitos mecanismos pelos quais ajuda o desenvolvimento tecnológico na sua tarefa de "resolver problemas" do qual pode-se destacar (Pavitt, 1998): i) conhecimento na forma de inputs úteis; ii) ferramentas e técnicas de projeto de engenharia - incluindo modelagem, simulação e previsão; iii) instrumentação; iv) cientistas treinados e engenheiros; v) background de conhecimento; vi) associação a redes nacionais e internacionais de profissionais; vii) empresas spin-off baseadas

\footnotetext{
${ }^{3}$ Será definido mais adiante
} 
no conhecimento acumulado e descobertas realizadas nas universidades. Embora, como 0 próprio Pavitt (1991) já havia advertido este impacto da ciência sobre a tecnologia é complexo, com a intensidade de transferência do conhecimento derivado da ciência básica para a tecnologia variando entre os diferentes setores da atividade econômica e da geração dessas tecnologias novas.

De fato, o entendimento moderno é que não existe uma dicotomia entre ciência básica e ciência aplicada, em particular, quanto aos seus objetivos, o que implica dizer que 0 relacionamento entre ciência (básica) e tecnologia não é linear, no qual muito do progresso tecnológico é derivado da ciência, mas grande parte do desenvolvimento tecnológico permite 0 avanço da ciência e define os rumos da ciência básica (Stokes, 2005). Pode-se pensar como argumenta Castells (2003), que existe uma tecnologia de geração e mesmo difusão do conhecimento, que é fruto de um conhecimento anterior acumulado a partir da ciência e que levará a novos aprimoramentos científicos no desenvolvimento da tecnologia de processamento de informações e reprodução do conhecimento em um ciclo que só se amplia.

Ademais, por suas características, para Pavitt (1991) a pesquisa básica necessariamente precisa da subvenção pública não só pela incerteza de ganhos para o ente privado, especialmente se o horizonte de planejamento das empresas é o curto prazo, mas porque a "política de sigilo" no enfrentamento dos imitadores será sub ótima, pois restringiria sua aplicação a um reduzido custo marginal.

Os resultados das externalidades positivas geradas pela educação, do qual derivam a pesquisa básica e aplicado no seu interior e nas redes de relações que se formam ao redor das universidades, torna a decisão de como elas vão ser adotadas pela sociedade (economia), como uma decisão estratégica. De um lado, seus efeitos positivos vão muito além de fatores de eficiência, e, portanto, deve ser relacionada com fatores de busca de equidade, com benefícios sociais, que tornam a sociedade no mínimo mais desigual e inclusiva. Ademais, pode significar a correção de rota de alguns mecanismos sociais históricos perversos, que exclui uma parte da população do bem-estar social em todos os níveis, divididas por grupos sociais ou de raça, a condições mais dignas e ou oportunidades de ascensão e mobilidade social.

Em verdade, como cita Chatterton; Goddard (2000) as universidades são cada vez mais completamente direcionadas para o desenvolvimento regional garantindo os mais diversos objetivos sociais e econômicos. As Universidades públicas do século XIX no Estados Unidos e na Inglaterra forneciam conhecimento e competências para as industrias locais como de engenharias e agricultura (Serra et al, 2018) 


\subsection{A HÉLICE TRÍPLICE E O PAPEL DA EDUCAÇÃO}

A abordagem de Sistemas de Inovação pode ser reforçada analiticamente pela definição dos "Sistemas Hélices" (Etzkowitz; Leydesdorff, 1997, 1998; Etzkowtz; Ranga, 2013; Carayannis, et al. 2018; Grundel; Dahlstrom, 2016). Esses sistemas podem ser entendidos como uma metodologia mais pragmática e objetiva para falar das relações dos principais agentes econômicos voltados para inovação, competitividade e desenvolvimento econômico que são: universidades e institutos de pesquisa, empresas e governo. Onde cada um deles se configura como uma hélice, formando assim, a Hélice Tríplice.

Em verdade, segundo Carayannis, et al (2018) pode-se pensar que o sistema hélice tríplice seja o "núcleo do modelo" sobre inovação, enquanto que a quarta hélice pode ser introduzida nesse sistema como sendo o da sociedade civil ou nas palavras dos autores "mediabased and cultura-based public" e que está associada a mídia, industrias criativas, culturas, valores, estilos de vida, arte, e uma noção de grupo criativo mediados pela democracia, num sentido em que ela associa a importância e o pluralismo e uma diversidade de agentes, atores e organizações (Carayannis; Campbell, (2009). Incluindo também ONGs e união de trabalhadores (associações) (Grundel; Dahlstrom (2016). Nesse sentido, o amplo entendimento da produção do conhecimento e aplicação da inovação requer que a sociedade torne-se mais integrada dentro do sistema de inovação. O entendimento é que a estrutura do Sistema de Inovação Quadruplo Hélice está num sentido de colocar os usuários de inovação a serviço da sociedade civil como um todo (Carayannis, et al.2012; 2018).

Por sua vez, o sistema Hélice Quíntupla representa o ambiente natural da sociedade. Segundo Grundel; Dahlstrom (2016), o modelo quíntupla hélice compreende: sistema educacional, sistema econômico, o meio ambiente natural, sociedade baseada na cultura e na mídia e o sistema político. Essas 5 hélices funcionam como subsistema, onde o conhecimento se move de um subsistema para outro num movimento circular e de forma acumulativa e crescente, de domo que a quinta hélice é mais propriamente entendida como um condutor para novos conhecimentos e inovações ao encontro das próprias interações entre sociedade e meio ambiente.

A Figura 4 representa de forma esquemática o processo de inovação como sugerido por Greenhalgh; Rogers (2010), considerando a participação dos três componentes da tríplice hélice. 
Figura 4: Processo de Inovação

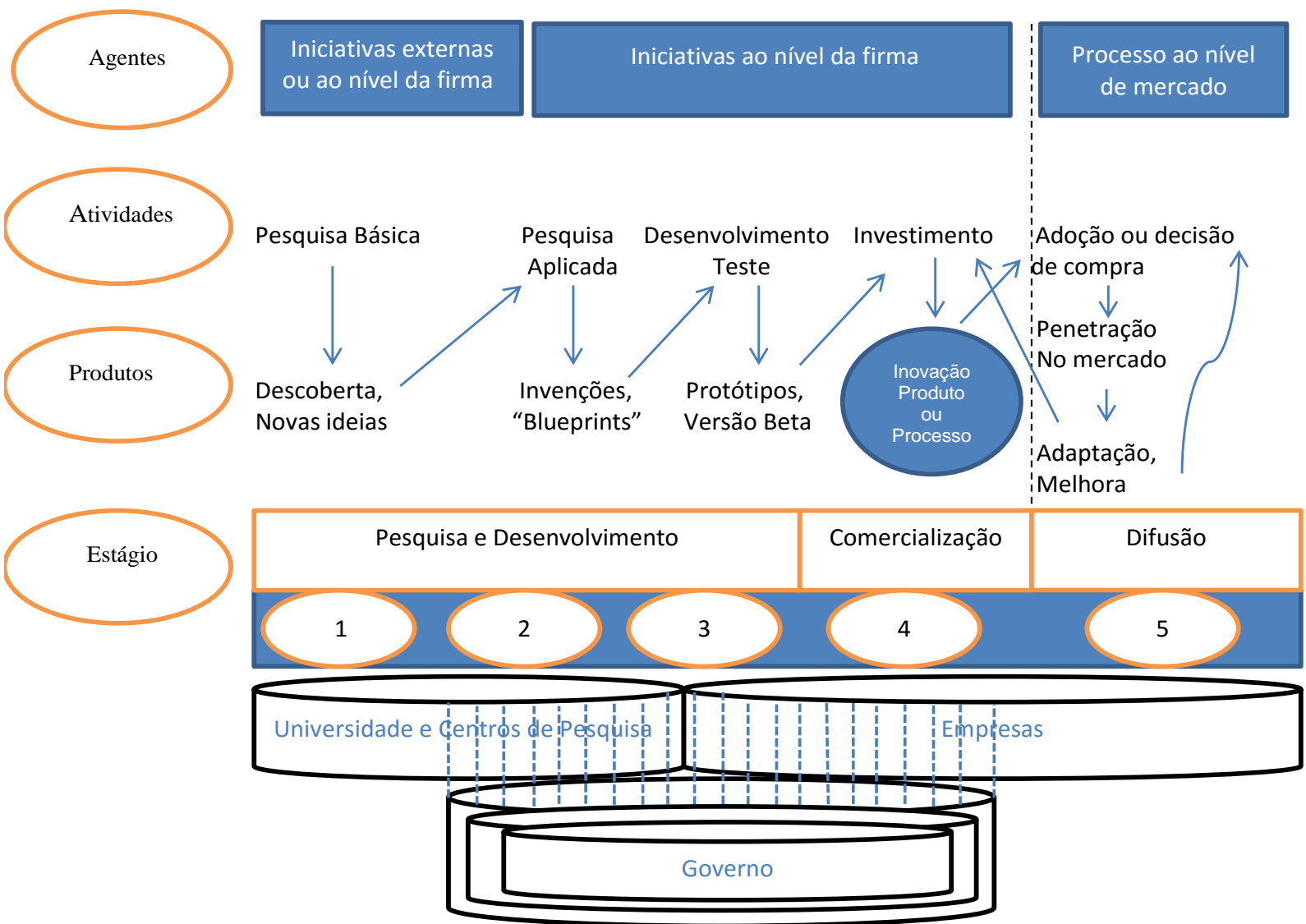

Fonte: Adaptado a partir de Greenhalgh; Rogers, 2010.

Em verdade, segundo Goddard (2007) as Instituições de Alto Nível Educacional ${ }^{4}$ além de nucleadoras da pesquisa (básica e aplicada) em interação com as empresas, devem interagir, também, com suas regiões (o local onde estão instaladas), recrutando estudantes de outros países, aumentando também as matriculas para população local, buscando renda adicional de serviços prestados a empresas locais por meio de consultoria e treinamento profissional, além do mais podem promover um ambiente local que atraia e retenha acadêmicos criativos e estudantes motivados. Em suma, essa instituição - universidade - pode demonstrar sua contribuição para a sociedade civil em que está inserida. Através de tais esforços (ou mesmo desafios), as instituições de ensino superior são capazes de fornecer evidências concretas do valor que 0 ensino superior e a pesquisa agregam ao investimento público (Goddard, 2007), potencializando seus resultados específicos em termos de indicadores de desempenho, mas ao mesmo tempo e expandindo e diversificando seu leque de externalidades sociais.

\footnotetext{
${ }^{4}$ Pode-se fazer uma analogia com as Universidades de Ensino Superior do Brasil.
} 
Corroborando com isso, mas entendendo que tudo isso se conforma como grandes desafios e obstáculos existentes sobre as próprias universidades atualmente, Kempton et el., (2014) enfatiza a crucial importância das universidades dentro dos seus sistemas regionais de inovação, especialmente naqueles onde o setor privado pode ser fraco ou relativamente pequeno e com baixos níveis de atividades de pesquisa e desenvolvimento (P\&D), e onde existe uma rica história de análises acadêmicas e políticas (Kempton et al, 2014). As universidades são um "ativo" crítico da região, em especial as menos favorecidas, e tem um papel dinamizador da própria atividade econômica.

Segundo esses autores, as "evidências mostram que a mobilização bem-sucedida dos recursos de uma universidade pode ter um efeito desproporcionalmente positivo nas economias regionais e na conquista de estratégias regionais abrangentes" (Kempton et al, 2014 p. 10).

No contexto atual, portanto, segundo Bedford (2018) as universidades são pensadas, em seus diferentes relacionamentos com a comunidade/atores sociais que contribuem com a inovação e difusão tecnológica e, portanto com o ecossistema de inovação por três formas: i) provisão de mão-de-obra apropriadamente mais habilitada (Capital Humano)- primeira missão; ii) avanços no conhecimento técnico e científico, via pesquisa acadêmica - segunda missão e iii) a partir da transferência de conhecimento e tecnologia da academia para a indústria e sociedade terceira missão (Bedford, 2018). Ou, pode-se pensar essa terceira missão como, segundo Kempton (et al 2014), Smart Specialisation Strategies (S3) - Estratégias de Especializações Inteligentes para países da União Europeia.

A necessidade da interação entre universidades e empresas sempre foi premente (Etzkowitz, 2016) a partir da $3^{\mathrm{a}}$. Revolução Industrial ${ }^{5}$. Na segunda metade do século XX em diante, pelo menos em países como Alemanha, Estados Unidos, França entre outros, a relação entre ciência e tecnologia é centrada tanto na formação de doutores pelas universidades com 0 objetivo principal de irem trabalhar nos grandes laboratórios de empresas, quanto de cientistas empreendedores dentro das universidades que estão hábeis a fazer a interação entre conhecimento e inovação, minimizar problemas de aprendizagem, decodificar conhecimentos

\footnotetext{
50 período da primeira Revolução Industrial compreende a segunda metade do século XVIII até meados do século XIX, ou melhor, de 1760 a 1860. A $2^{\mathrm{a}}$. Revolução Industrial compreende os anos de (1850/1870) final sec XIX entrando no sec XX até aproximadamente1939/1945. Uma de suas caracterizações é que a partir daí surge a produção em massa. A $3^{a}$. Revolução Industrial começa a partir do final da 1a. metade do século XX - 1960, caracterizada como a revolução digital ou do computador, onde a produção enxuta, e uso intensivo da Tecnologia da Informação (TI) são preponderantes. Por sua vez, o início da $4^{a}$. revolução Industrial se dá com a internet difundida já a partir de 1989 e com o advento da indústria 4.0.É importante notar que a 3a . e a 4a. revoluções industriais se confundem no tempo e que as datas consideradas divergem um pouco de autor para autor( SCHWAB, 2016; VIALE \& ETZKOWITZ, 2005; SACOMANO et al, 2018).
} 
tácitos e analisar as inovações que são potencialmente comerciáveis - em verdade, a Universidade Empreendedora (Viale; Etzkowitz, 2005).

A universidade passa a ser o centro de todo processo voltado para a inovação, tecnologia para a atividade produtiva e assim, consequentemente para o desenvolvimento econômico. Elas são as principais formadoras e acumuladoras do principal insumo da sociedade do conhecimento, o conhecimento científico e, por essa via, concorrem de forma significativa para a intensidade de invenções a partir de meados do século $X X$ até hoje, mas também vêm assumindo novas funções decisivas nessa sociedade, com um ator ativo de transformações. $A$ chamada Universidade Empreendedora faz ciência e transforma invenções em inovações - novo paradigma acadêmico empreendedor. É a universidade na promoção de desenvolvimento socioeconômico como resultados dos esforços acadêmicos. A condição estratégica do conhecimento, educação e das universidades na sociedade contemporânea, portanto, requer sua condição, enquanto, pública, gratuita, universal e capilarizadora e transformadora dos locais por onde ela atua.

\section{CONSIDERAÇÕES FINAIS}

Por tudo descrito acima, pode-se entender a importância da educação em todos os níveis, especialmente, a educação em nível superior.

No que se referem às universidades, protagonistas do processo de desenvolvimento atual, sempre passaram por transformações significantes em relação as suas funções e objetivos. De acordo com a evolução da sociedade, pelo menos nos países ocidentais, as universidades evoluíram modificando o modo de pensar e agir de professores, pesquisadores e todo o corpo de trabalhadores dessas instituições.

Desde a chamada Torre de Marfim até os dias de hoje a demanda por universidades mais "objetivas", "pragmáticas", orientadas para a realidade social e econômica da região (local) onde se inserem, tem crescido substancialmente e ela tem atendido esse chamamento. A forma como o conhecimento evoluiu e tornou-se o principal insumo das economias modernas, por qual atravessam a $3^{\text {a }}$ e $4^{\text {a }}$ Revolução Industrial, acentua a necessidade de um tratamento especial e estratégico ao conhecimento e a educação, seja pelas externalidades que geram e, portanto, seus benefícios sociais, seja pela condição de promotora de capital humano, realização da pesquisa científica (básica e aplicada) e, portanto, como elemento fundamental de convergência de competências para inovação e transformações sociais dela decorrentes, em seu "novo" papel empreendedor. 
Um ponto interessante a pensar, que vai ao encontro à universidade puramente empreendedora é que segundo Angelini (2015), foi exatamente com a torre de marfim gaussiana que nasceu a própria ciência como a entendemos e confiamos hoje. E ainda, para que a ciência tenha alguma aplicabilidade é necessário antes contemplar, ou mesmo teorizar. Entretanto, a própria comunidade acadêmica reclama que as universidades (IFES brasileiras) só fazem teoria. Ou seja, técnicos administrativos, alunos e uma boa parcela dos próprios professores.

Outro ponto interessante a pensar e consequência do anterior é que se a universidade não fizer teoria, e experimentos em laboratórios (com alunos de pós graduação, por exemplo) quem fará? Segundo ainda o mesmo autor acima, sem o conhecimento da teoria e da capacidade de filosofar ${ }^{6}$ sobre ela, fica difícil o desenvolvimento da ciência em si e consequentemente sua aplicabilidade.

Ao mesmo tempo, a força da universidade está na sua "liberdade de expressão", na codificação do conhecimento a partir da realidade empírica, ao mesmo tempo, que a possibilita transformá-la. Sua base de sustentação no Sistema de Inovação e sua capacidade empreendedora é resultado das próprias características do conhecimento e da pesquisa básica como bens públicos, e como bem comum universal. Assim, muito além de sua eficiência, a importância da universidade produtora de conhecimento, tem que ser pensada como mediadora social e papel de equidade.

\footnotetext{
${ }^{6}$ A expressão PhD vem de Philosophy Doctor (Angelini, 2015)
} 


\section{REFERÊNCIAS BIBLIOGRÁFICAS}

ANAND, P. B. Financing the provision of global public goods. World Institute for Development Economic research. Heksink, Finland: ONU/WIDER, 2002. Discussion Paper No. 2002/110.

ANGELINI, R. Defendendo a torre de marfim. Universidade Federal do Rio Grande do Norte, Departamento de Engenharia Civil Boletim ABLimno 41(2), 15-19, 2015

BAUMOL, W.J.; OATES, W. The Theory of Environmental Policy. Cambridge University Press, Cambridge, 1988. https://doi.org/10.1017/CBO9781139173513

BECKER, Gary S. Human capital. A theoretical and empirical analysis with special reference to education. $3^{a}$ ed. Chicago and London: The University of Chicago Press, 1992.

BECKER, Gary S. Investment in human beings. The Journal of Political Economy Vol. LXX, No. 5, Part 2 (University of Chicago Press), 1962.

BENHABIB, J., SPIEGEL, M. M. The role of human capital in economic development: evidence from aggregate cross-country data. Journal of Monetary Economics, v.34, n.2, p.143-173, 1994.

BARRO, Robert, J. 2001. Human Capital and Growth. American Economic Review, 91(2):1217.

BAUM, S.; PAYEA, K. Education pays 2004. The benefits of higher education for individual and society. The College Board. (Trends in higher education series).

CARLOTTO, Maria Caramez. Veredas da mudança na ciência brasileira. Discurso, institucionalização e práticas no cenário contemporâneo. São Paulo: Editora 34, 2013.

CASTELLS, Manuel. A sociedade em rede. Volume I. São Paulo: Paz e Terra, 2002.

CHATTERTON, P.; GODDARD, J. The Response of Higher Education Institutions to

Regional Needs. European Journal of Education, Vol. 35, No. 4, 2000

CHIARINI, T.; VIERA, K. P. Universidades como produtoras de conhecimento para 0 desenvolvimento econômico: sistema superior de ensino e políticas de C T \& I. RBE, Rio de Janeiro, v. 66, n.1, p. 117-132, jan-mar, 2012.

CEPAL. UNESCO. Educação e conhecimento: eixo da transformação produtiva com equidade - Brasília: IPEA/CEPAL/INEP, 1995.

CIMOLI, Mario. National System of Innovation: a note of technological asymmetries and cathing up perspectives. Rio de Janeiro: UFRJ. Revista de Economia Contemporânea 18 (1), p. 5-30, 2014.

CURY, Carlos Roberto Jamil. Graduação/pós-graduação: a busca de uma relação virtuosa. Educação e Sociedade, Campinas, v. 25, n. 88, p. 777-793, out. 2004.

DAVID, P. A.; THOMAS, M. (Eds). The economic future in historical perspective. New York: Oxford University Press, 2006.

DAVID, Paul. A.; FORAY, Dominique. Economic fundamentals of knowledge society. Police Futures in Education, Volume 1, Number 1, 2003.

DASGUPTA, Partha; DAVID, Paul A. Toward a new economics of science. Research Policy 23 (1984), p. 487-521.

ETZKOWITZ, H..; LEYDESDORFF, L. Universities and the Global Knowledge Economy: A Triple Helix of University-Industry-Government Relations. London: Pinter, 1997.

ETZKOWITZ, H.; LEYDESDORFF, L. The Endless Transition: A "Triple Helix" of UniversityIndustry-Government Relations, Introduction to a Theme Issue. Minerva, 36, 1998, p.203-208.

ETZKOWITZ, H. Hélice Tríplice: universidade - indústria - governo: inovação em ação / Henry Etzkowitz. - Porto Alegre: EDIPUCRS, 2009. xiv+207 p.

ETZKOWITZ , H (2016) Industry \& Higher Education Vol 30, No 2, April 2016, pp 83-97, doi: 10.5367/ihe.2016.0303 
ETZKOWITZ, H. Innovation in Innovation: The Triple Helix of University-Industry-Government relations. Social Science Information. 2003. 42: 293. DOI: 10.1177/05390184030423002.

GORDON, J. L. P. L. Sistema Nacional de Inovação: uma alternativa de desenvolvimento para países da América Latina. Anais do XIV Encontro Nacional de Economia Política. Sociedade Brasileira de Economia Política - SEP. São Paulo, 2009.

IOSCHPE, Gustavo. A ignorância custa um mundo. 0 valor na educação no desenvolvimento do Brasil. $2^{\mathrm{a}}$ Ed. Rio de Janeiro: Objetiva, 2016. P. 49-111.

KAUL, I.; MENDOZA, R. Advancing the Concept of Public Goods. IN: KAUL, I.; CONCEIÇÃO, P.; GOLVEN, K.; MENDOZA, R. (Orgs.). Providing global public goods: managing globalization. United Kingdom: Oxford University Press, 2003. p. 78 - 111.

KAUL, I.; GRUNBERG, I.; STERN, M. Definindo Bens Públicos Globais. IN: Bens Públicos Globais. 1. ed. Rio de Janeiro: Editora Record, 2012. p. 45 - 58.

KAUL, I. Private Provision and Global Public Goods: Do the Two Go Together? Global Social Police, v. 5, n. 2, p. 137 - 140, 2005. DOI: 10.1177/146801810500500203

KAUL, I.; MENDOZA, R. Advancing the Concept of Public Goods. IN: KAUL, I.; CONCEIÇÃO, P.; GOLVEN, K.; MENDOZA, R. (Orgs.). Providing global public goods: managing globalization. United Kingdom: Oxford University Press, 2003. p. 78 - 111.

KEMPTON L, GODDARD J, EDWARDS J, HEGYI FB, ELENA-PÉREZ S. Universities and Smart Specialisation. Seville: Institute for Prospective and Technological Studies, Joint Research Centre, 2014. JRC Technical Reports; S3 Policy Brief Series JRC85508. European Union, 2014

KOLSTAD, C. D. Environmental economics. New York: Oxford University Press, 2000.

LUNDVALL, B. A. \& CHRISTENSEN, J. L. Extending and deepening the analysis of innocation system: With empirical illustrations from the DISCO-project. Working Paper 9912, DRUDI, 1999.

LUCAS, Robert. On the Mechanics of Economic Development, Journal of Monetary Economics. Vol.22, 3-42, 1988.

LUNDVALL, B. A. National Innovation System - Analytical concept and development tool. DRUID-conference in Copenhagen June 27June 29, 2005.

MANKIW, Gregory; ROMER, David and WEIL, David. A Contribution to the Empirics of Economic Growth, Quarterly Journal of Economics, Vol. 107, 407-8, 1992.

MARGINSON, S. The public/private divide in higher education. A global Revision. . Higher Education, Vol. 53: 307-333, 2007.

MARGINSON, S. Higher education and public good. Higher Education Quaterly, Vol. 65, No. 4, outubro de 2011, p 411-433.

MINCER, J. Investment in Human Capital and Personal Income Distribution. The Journal of Political Economy, v.66, n.4, p.281-302, 1958.

MISHAN, E. J. The postwar literature on externalities: an interpretative essay. Journal of Economic Literarture, Vol. 9, No 1, p 1-28, 1971.

MOWERY, D. C.; ROSENBERG, N. Paths of innovation. Technological change in 20th-Century America. Cambridge, United Kingdom: Cambrige University Press, 1999.

NAKABASHI, Luciano. Três ensaios sobre o capital humano e renda por trabalhador. Belo Horizonte, UFMG, 2005. (Tese de Doutorado em Economia).

NELSON, R. R.; PHELPS, E. S. Investment in Humans, Technological Diffusion and Economic Growth. American Economic Review LVI, 1966: 69-75.

ORGANIZAÇÃO DAS NAÇÕES UNIDAS PARA A EDUCAÇÃO, A CIÊNCIA E A CULTURA. Relatório UNESCO sobre Ciência 2010. 0 atual status da ciência em torno do mundo. Resumo Executivo. UNESCO: Susan Scheegans, 2010. 
OLIVEIRA, Terezinha. Origem e memória das universidades medievais. A preservação de uma instituição educacional. Belo Horizonte, MG: Varia História, Vol. 23, $n^{0}$ 37, jan./jun.. 2007. p. 113-129.

PAVITT, Keith. What make basic research economically useful ?. Research Policy, 20, p.109119, 1991.

PAVITT, Keith. The social shaping of the national sicence base. Research Policy, 27, p.793-805, 1998.

PEREIRA, Paulo Trigo. O conceito económico de bem público. Em: João Pato; Luísa Schmidt; Maria Eduarda Gonçalves (organizadores). Bem comum Publico elou privado ?. Portugal, Lisboa: Imprensa de Ciências Sociais, 2013. p. 85-108.

PERELMUTER, Guy. Futuro presente. 0 mundo movido à tecnologia. Jaguaré, SP: Companhia Editora Nacional, 2019.

REZENDE, Sérgio Machado. Momentos da Ciência e Tecnologia no Brasil: uma caminhada de 40 anos pela C\&T. Rio de Janeiro: Vieira \& Lent, 2010.

RIBEIRO, Maria das Graças. A educação superior norte-americana: gênese de um modelo. Hist. Educ. (on line). Porto Alegre, Vol. 20, nº 48, jan./abril, 2016, p. 7593.

RIFKINS, Jeremy. A Terceira Revolução Industrial. Como o poder lateral está transformando a energia, a economia e o mundo. São Paulo: M. Brooks do Brasil, 2012.

ROGERS, E. Diffusion of innovations. 4 ed. New York: Free Press, 2003. 523 p.

ROMER, Paul M. Increasing Returns and Long-Run Growth, Journal of Political Economy, Vol. 94, Issue 5, October, 1002-1037, 1986.

ROMER, Paul. Endogenous Technological Change, Journal of Political Economy 98, S71S102, 1990.

ROMER, M. Paul. The Origens of Endogenous Growth, Journal of Economic Perspectives, Vol. 8, No 1, winter, 3-22, 1994.

ROMER, Paul. Idea Gaps and Object Gaps in Economic Development. Journal of Monetary Economics, 32, 543-573, 1993.

ROSENBER, N.; NELSON, R. R. American universities and technical advance in industry. Research Policy 23, 323-348, 1994.

ROCKSTRÖM, J. Managing the global commons: Our worldview, goals and rules need to change in the new, less certain, epoch of the Anthropocene. Our Planet, p. 26-28, out. 2017.

SACOMANO, J.B.; GONÇALVES, R.F.; SILVA, M.T.da,; BONILLA, S.H.; SÁTYRO, W.C. (org). Indústria 4.0 - conceitos e fundamentos. São Paulo: Blucher, 2018. 182p.: il.

SAUL, Renato P. As raízes renegadas da teoria do capital humano. Sociologias. Porto Alegre, ano. 6, no 12, jul./dez., 2004, p. 230-273.

SERRA, M.; ROLIM, C.; BASTOS, A.P.(org). Universidades e Desenvolvimento Regional: as bases para a inovação competitiva. Rio de Janeiro: Ideia D, 2018

SCHOR, Tatiana. Ciência e tecnologia. 0 caso de experiment de grande escala da biosferaatmosfera na Amazônia (LBA). São Paulo: Annablume; Fapesp; Anppas, 2008. (Coleção Cidadania e Meio Ambiente.

SCHWAB, K. A Quarta Revolução Industrial. Tradução Daniel Moreira Miranda. São Paulo: Edipro, 2016

SHAPIRO, C.; VARIAN, HAL R. A economia da informação. Como os princípios econômicos se aplicam à era da internet. Tradução Ricardo Inojoso. Rio de Janeiro, Elsevier, 1999.

SCHULTZ, Theodore, W. Investment in Human Capital. The Free Press, New York, 1961.

STIGLITZ, J. E. knowledge as global public good. In: Kaul, I.; Grunberg, I.; Stern, M. A. Global public goods: international cooperation in 21st century. New York, NY, Oxford University Press, 1999. p 308-325. 
STIGLITZ, J. E. Public Policy for a Knowledge Economy. Remarks at the Department for Trade and Industry and Center for Economic Policy Research, London, 27 January. 1999b. Available at: http://www.worldbank.org/html/extdr/extme/jssp012799a.htm

STOKES, Dnald E. 0 quadrante de Pasteur. A ciência básica e a inovação tecnológica. Traduação José Emílio Maiorino. Campinas, SP: Editora da UNICAMP, 2005.

VIALE, R. \& ETZKOWITZ, H. Third academic revolution: polyvalent knowledge, The "DNA" of the Triple Helix." in Triple Helix 5. Turin, Italy, 2005.

VIOTTI, Eduardo Baumgratz; MACEDO, Mariano de Mattos (Org.). Indicadores de Ciência, tecnologia e inovação no Brasil. Campinas, SP: Editora da UNICAMP, 2003.

WARSH, David. Knowledge and the Wealth of Nations. A story of economic discovery. New York: W. W. Norton \& Company. 2006.

WERTHEIN, J.; CUNHA, C. Investimentos em educação, ciência e tecnologia. 0 que os economistas pensam. Brasília: UNESCO Brasil. Ministério da Educação, Instituto Sangari, 2004.

Recebido para avaliação em Junho de 2019.

Aceito para Publicação em Outubro de 2019. 


\title{
PESQUISA CIENTÍFICA, CONHECIMENTO E EDUCAÇÃO: REFLEXÕES SOBRE SUA IMPORTÂNCIA ECONÔMICA E SOCIAL
}

\section{Resumo}

Um dos diferenciais do século XXI é a importância que a informação assumiu na vida cotidiana à medida que as tecnologias de informação e comunicação criaram e massificaram uma "nova economia", ditando um novo paradigma assentado em cinco características principais: informação como a matéria-prima sob a qual tecnologia hegemônica age; capacidade de penetração dessas tecnologias a lógica das redes em criar interações e conexões potencializando a difusão dessas informações; a flexibilidade com que processos, organizações e instituições podem ser modificadas e, por fim a convergência tecnológica em tornar a informação acessível e de certo modo útil. Dada à condição diferencial da produção e disseminação do conhecimento, especialmente, a partir da educação, interessa entender sua condição estratégica na economia contemporânea, daí o objetivo principal deste artigo: discutir a interpretação da ciência econômica acerca da educação e da produção do conhecimento via pesquisa, desenvolvimento, ciência e inovação, inclusive, ressaltando o papel do Estado e da política pública em sua promoção e disseminação. Ao encontro do objetivo acima este artigo está divido em três seções, a primeira discute os fundamentos teóricos do conhecimento e da educação, enquanto geradores de externalidades e com características de bens públicos. A seção 2 discute a discussão da Teoria do Capital Humano no entendimento do conhecimento e educação. A terceira seção apresenta a discussão neochumpteriana consoante às abordagens dos Sistemas de Inovação e Hélice Tríplice e o papel das Universidades na Produção do Conhecimento e Inovação. A quarta seção tece algumas considerações finais.

\section{Palavras-chave: Inovação, Teoria do Capital Humano, Universidade Pública}

\begin{abstract}
One of the differentials of the 21 st century is the importance that information has assumed in everyday life as information and communication technologies have created and massified a "new economy", dictating a new paradigm based on five main characteristics: information as the raw material under which hegemonic technology acts; capacity of penetration of these technologies the logic of the networks in creating interactions and connections potentiating the diffusion of this information; the flexibility with which processes, organizations and institutions can be modified and, finally, technological convergence in making information accessible and somewhat useful. Given the differential condition of knowledge production and dissemination, especially from education, it is interesting to understand its strategic condition in contemporary economy, hence the main objective of this article: to discuss the interpretation of economic science about education and the production of knowledge via research, development, science and innovation, including, highlighting the role of the State and public policy in its promotion and dissemination. To meet the above objective, this article is divided into three sections, the first of which discusses the theoretical foundations of knowledge and education, as generators of externalities and with characteristics of public goods. Section 2 discusses the discussion of the Human Capital Theory in understanding knowledge and education. The third section presents the Neochumpterian discussion according to the approaches of the Innovation Systems and Triple Helix and the role of Universities in the Production of Knowledge and Innovation. The fourth section makes some final considerations.
\end{abstract}

Keyword: Innovation, Theory of Human Capital, Public University 